\title{
COMBATE AO PANSTRONGYLUS MEGISTUS COM O MALATHION CONCENTRADO*
}

\author{
Italo A. Sherlock e Tácito M. Muniz
}

O Malathion concentrado ( 0 - 0 dimetilfosforo ditioato de dietil mercapto - succinato) foi usado para combater o Panstrongylus megistus, principal vector da doença de Chagas, numa zona endêmica do Estado da Bahia.

A eficácia do malathion no controle desse triatomíneo foi constatada após ter sido aplicado três vezes, no periodo de um ano e meio, em intervalos semestrais. A ação letal do inseticida tanto se faz sobre as formas ambulantes, como sobre os ovos de P. megistus.

Em vista da eficácia para o controle do triatomíneo, de não terem sido observados efeitos tóxicos colaterais para o homem e do custo operacional ser relativamente baixo, os Autores concluem que o malathion é uma arma valiosa para uso nas campanhas contra os - transmissores da doença de Chagas.

É possível, através de um programa bem conduzido, controlar o $P$. megistus com o B.H.C., a um baixo nivel populacional que possa ser considerado de pequena significância na transmissão do Trypanossoma cruzi para o homem $^{3}, 6,7$. Entretanto, além dos efeitos tóxicos para o homem e animais domésticos, alguns fatores entre os quais o custo operacional relativamente elevado, causado principalmente pela necessidade da reaplicação freqüente do inseticida que tem o seu efeito residual inativado pelo barro das paredes das casas, fazem com que se procurem outras substâncias que possam oferecer melhores resultados no combate aos vetores da doença de Chagas.

Entre outros inseticidas, o malathion foi recentemente utilizado por Martinez e Cols. ${ }^{4}$ na Argentina, no combate a $T$. infestans onde os seus resultados foram considerados satisfatórios, inclusive por possuir o inseticida ação letal sobre os ovos de triatomíneos. Sobre essa ação ovicida que conseguimos confirmar recentemente, já publicamos um trabalho anterior ${ }^{8}$.
Em novembro de 1972, a "BLEMCO", representante do malathion no Brasil, através da Diretoria do INERU, solicitou-nos a organização de um programa para experimentar o produto no campo para combater ao $P$. megistus, principal vetor da doença de Chagas na Bahia.

Apresentamos, neste trabalho, os resultados que obtivemos com a aplicação do malathion, durante três anos, numa pequena área do Estado da Bahia, infestada por P. megistus.

\section{A ÁREA DE TRABALHO}

Na zona denominada de "Recôncavo" do Estado da Bahia, localizam-se as fazendas do - Município de Castro Alves, onde trabalhamos. Os levantamentos para triatomíneos antes realizados $^{9}$ e a existência de casos de doença de Chagas definiram a área como endêmica para a tripanossomose. A única espécie de triatomíneo ali encontrada no interior das habitações, por sinal albergando elevado indice de infecção pelo T. cruzi, foi o Panstrongulus megistus, que é

* Trabalho do Núcleo de Pesquisas da Bahia do INERU - FOC

Salvador, Bahia, Brasil. "Malathion" - produto sintetizado pela American Cyanamid Company, distribuído no Brasil com o nome comercial de Malatol $100 \mathrm{E}$.

Recebido para publicação em 29/7/75. 

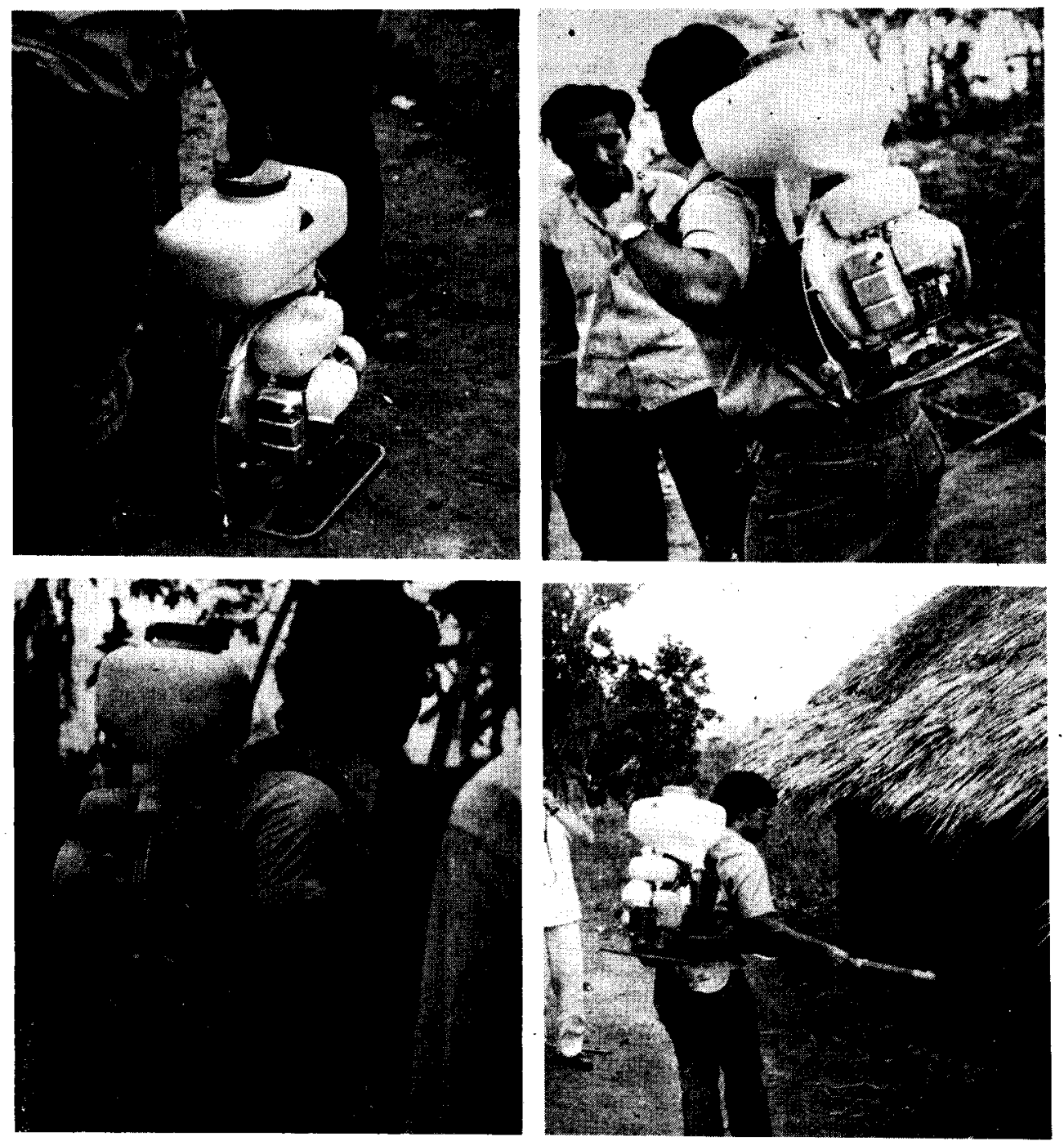

Figs. 1 a 4 - Aplicação do Malathion com a bomba Fontan R 11 para combater o $P$. megistus principal vetor da doença de Chagas numa área endêmica do Estado da Bahia. 
incriminado como o principal transmissor de doença no Estado da Bahia ${ }^{10}$.

Das nove fazendas incluídas no plano, a mais próxima da Cidade de Castro Alves distava cerca de $12 \mathrm{~km}$ através de estrada de rodagem Algumas fazendas, entretanto, eram bastante afastadas e localizadas em terrenos acidentados, não nos tendo sido possível visitá-las com veículos motorizados.

Previamente à aplicação do inseticida em 1973, fizemos um recenseamento da população e um mapeamento geográfico da área. O total de habitantes encontrado nesse censo foi de 871 pessoas, as quais viviam em 194 casas existentes nas nove fazendas abrangidas pelo projeto.

\section{MÉTODOS DE TRABALHO}

Procuramos adaptar o nosso programa às condições do Brasil, onde, na prática, principalmente por motivos de ordem burocrática, só é possível de se realizar um programa de controle de vetor se esse exigir no máximo uma aplicação semestral de inseticida. Por isso, o nosso plano foi de realizar duas aplicações anuais, durante um ano e meio, ao contrário do trabatho de Martinez e Cols. ${ }^{4}$, cujo intervalo de aplicação do malathion para combate ao $T$. infestans foi muito mais curto.

Por outro lado, também levamos em consideração, com base nos nossos dados de laboratório, que uma geração de $P$. megistus não se desenvolve antes de um período de 6 meses, embora as fêmeas desse hemíptero possam ovipar com intervalos de poucos dias.

Selecionada a área, foi feita uma inspeção preliminar com desalojante de piriza nas 194 casas para determinação da densidade de triatomíneos, através da média horária de $P$. megistus coletados e do índice de infestação domiciliar por esse hemíptero.

A área total abrangida pelas 194 casas foi subdividida em 3 sub-áreas, nas quais se procedeu da seguinte forma:

Plano A - Área com borrifação total - Foi feita a borrifação com malathion de todas as casas existentes, de 6 em 6 meses. Do total de 86 casas, 24 esta- vam inicialmente infestadas por triatomíneos $(27 \%)$.

Plano B - Área com borrifação seletiva - Foi feita a borrifação com malathion somente das casas que se mostravam positivas nos levantamentos de $6 \mathrm{em}$ 6 meses com piriza. Do total de $\mathbf{4 9}$ casas, 12 estavam infestadas por triatomíneos no inquérito preliminar $(24 \%)$.

Plano C - Área controle - Apenas foram realizados os levantamentos com piriza no início e no fim do projeto, tendo no levantamento prévio um total de 41 casas, das quais 8 estavam infestadas por triatomíneos (19\%).

Todos os triatomíneos coletados foram identificados e examinados para tripanossomas, encontrando-se a única espécie $P$. megistus, com o índice global de $38 \%$ de infecção natural pelo T. cruzi.

Todas as casas foram borrifadas, tanto as paredes interiores como exteriores, quase que regularmente, conforme havíamos programado, tendo-se iniciado a primeira borrifação cerca de 30 dias após o levantamento preliminar. Na área seletiva, era realizado um levantamento semestral com piriza e após aplicado o inseticida. No final da programação, foi feito um novo levantamento para triatomíneos em todas as três áreas. $O$ inseticida foi aplicado por meio da bomba "Fontan", que é descrita a seguir na parte de material. Os tetos das casas não foram borrifados porque o $P$. megistus só acidentalmente o freqüenta.

Periodicamente foram demolidas algumas casas borrifadas para verificação do efeito ovicida do inseticida, cujos resultados foram apresentados em trábalho anterior, como já referimos ${ }^{8}$.

Paralelamente, foram feitas observações sobre a prevalência da infecção por $T$. cruzi tanto em pessoas como em animais domésticos. Estes resultados serão analisados no futuro próximo para verificar como se comportou o índice de infecção humana, antes e após as medidas de combate ao vetor. 


\section{MATERIAL}

O malathion concentrado é um inseticida líquido sintetizado pela "American Cyanamid Company" e lançado comercialmente em 1952, tendo sido utilizado por vários países para controle de diversas pragas da agricultura e também em campanhas de combate a mosquitos ${ }^{5}$.

Quimicamente é o 0,0 - dimetil fosforoditioato de dietil mercaptoșuccinato, com uma pureza de $96 \%$ no produto comercial. É estável por um período ilimitado se guardado em recipientes vedados em temperatura ambiente $\left(25^{\circ} \mathrm{C}\right)$ e protegido da luz. Entretanto, não persiste por muitos dias no solo ou água, sendo por isso de efeito tóxico acumulativo quase nulo para o homem. $O$ odor, após aplicado, é desagradável, lembrando couro podre.

A dose letal oral para ratos é LD $50 \mathrm{mg} / \mathrm{kg}=1.000 \mathrm{e}$ a cutânea LD $50 \mathrm{mg} / \mathrm{kg}=4.444$, portanto muito baixa, em comparação com o BHC e DDT, cujas doses orais e cutâneas LD $50 \mathrm{mg} / \mathrm{kg}$, são respectivamente de $430-690$ e $118-2.510^{5}$.

$O$ líquido que utilizamos nos foi gentilmente fornecido pela "Blemco Importadora e Exportadora", sua representante no Brasil.

Segunda a nossa observação pessoal, parece que a ação do malathion sobre o triatomineo é feita principalmente por contacto. Ao lado de seu efeito letal para as formas ambulantes do hemíptero, tem potente ação ovicida, impedindo o desenvolvimento embrionário ${ }^{4,8}$. 0 seu efeito residual é muito curto, atingindo provavelmente, no campo, um máximo de 15 dias, após borrifado e exposto às condições naturais ${ }^{8}$.

Não observamos, através de sinais e sintomas clínicos, efeitos colaterais tóxicos importantes tanto para o homem como para animais domésticos, durante o nosso programa em todas as aplicações do malathion. Entretanto, durante a aplicação é irritante para as mucosas respiratórias e ocular, provocando tosse e lacrimejamento. Por isso, aconselhamos o uso de máscara e a retirada dos moradores, durante a aplicação do inseticida.

Para melhores esclarecimentos quanto aos efeitos tóxicos para o homem, embora nas nossas observações a grosso modo, não os tenhamos verificado, sugerimos a consulta do trabatho de Culver, ${ }^{2}$, onde podem ser encontradas observações detalhadas a respeito.

Para a aplicação do malathion utilizamos a bomba FONTAN R 11 com bico de $0,8 \mathrm{~mm}$ movida a gasolina, com mecanismo de ventoi- nhas que giram cerca de 7.000 r.p.m. e dão uma saída de $510 \mathrm{~m}^{3} /$ hora de inseticida, com a velocidade de $95 \mathrm{~m} / \mathrm{segundo}$. A carga máxima da vasão da bomba é de 0,138 litros por minuto ${ }^{1}$ (Figs. 1 a 4 ).

O combustivel para movimentar a bomba é uma mistura de óleo de 2 tempos com gasolina, na razão de $1 / 25$, sendo o consumo aproximado de 1,2 litros por hora de trabalho. O reservatório de combustivel é de 1,2 litros.

A capacidade de armazenamento de malathion é de 10 litros. Na prática, verificamos que, para a borrifação de $124 \mathrm{~m}^{2}$ de superfície de parede, durante 5 minutos, foram gastos $308 \mathrm{ml}$ de malathion.

A bomba vazia pesa $9,4 \mathrm{~kg}$; entretanto, carregada com o combustível e com o inseticida, pesa cerca de $20 \mathrm{~kg}$, sendo este possivelmente um dos únicos inconvenientes para o seu uso na rotina de aplicação de inseticidas. Devemos ter em mente que, na nossa zona rural, as casas ficam afastadas umas das outras, as vezes de difícil acesso, sendo necessário o deslocamento a pé, através de morros e serras, para as realizações das borrifações. Entrętanto, pela rapidez com que se consegue fazer a borrifação das casas, é vantajoso o seu uso tanto para a economia de tempo como de verba, dando assim uma excelente produtividade. Os próprios guardas borrifadores a consideraram com algumas vantagens, apesar do peso, sobre as bombas Hudson $x$ Pert e Blemco, que são usadas atualmente nas campanhas do Ministério da Saúde.

$O$ inseticida foi aplicado como planejado, algumas vezes, no entanto, com discreto atraso de dias. Seis meses após a última borrifação, foi feito um levantamento para triatomíneos, quando foram obtidos os resultados que a seguir apresentamos.

\section{RESULTADOS}

\section{Plano A - Borrifação semestral de todas as casas.}

$\mathrm{Na}$ Tabela I verificamos que nas 4 fazendas compreendidas nesse projeto, existiam, previamente à aplicação do malathion, 96 casas, das quais 86 foram investigadas, havendo 24 infestadas por triatomíneos (27\%). A densidade global de triatomíneos para essa área foi de 7,2 triatomíneos por hora.

Nessa área foi aplicado o malathion semestralmente, durante um ano e meio, num total de três aplicações. Após seis meses da última aplicação, foi feito um levantamento com piriza para a avaliação dos efeitos e os resultados estão detalhados na Tabela II; das 93 casas existentes, 
91 foram então investigadas, estando entre elas 8 infestadas por triatomíneos, dando uma densidade global de 1,7 triatomíneos por hora. Houve, portanto, uma queda muito drástica no índice de infestação das casas e na densidade de triatomíneos.

Entretanto, algumas casas se mantiveram positivas, embora com densidade de triatomíenos muito mais baixas que as obtidas previamente à aplicação de malathion, como a fazenda Caco que, antes do trabalho, possuia $53 \%$ das casas infestadas e 18,4 triatomíneos por hora, acusando, no final da observação, $18 \%$ de casas infestadas e uma densidade de 5,7 triatomíneos por hora. Vê-se, portanto, que o malathion teve potente ação contra os triatomíenos, eficácia ainda mais evidente se os resultados foram comparados com os obtidos na área "Controle". Nesta, inicialmente às observações, existiam $19,5 \%$ de casas infestadas e 3,2 triatomíneos por hora, enquanto que no inquérito final essas taxas subiram para $27 \%$ de casas infestadas e uma média horária de 5,3 triatomíneos por hora.

Plano B - Borrifação semestral seletiva das casas positivas.

Nesta área, cujos dados também estão nas Tabelas I e II, inicialmente existiam 50 casas das quais 49 foram investigadas com piriza. havendo $24 \%$ infestadas com um indice de 14,1 triatomineos por hora.

No final do trabalho, seis casas haviam sido destruidas pelos habitantes; entretanto, não foram as positivadas inicialmente, de modo que os resultados não estão mascarados. Contudo, três das casas positivas inicialmente, durante o curso do trabalho, tiveram demolidos e reconstruidos os seus quartos de dormir, para a verificação do efeito ovicida do malathion. Essa demolição. assim como os levantamentos semestrais certamente influenciaram para baixar o indice de infestação das casas e principalmente a densidade de triatomíenos nessa área, dando a impressão de uma maior eficácia do inseticida neste programa seletivo.

No final do programa, os dados globais obtidos após 3 aplicações do malathion durante um ano e meio e a avaliação final após seis meses da última borrifação, demonstraram ainda 10\% de casas infestadas e uma densidade de 1,3 triatomíenos por hora, entretanto inferiores as cifras obtidas no início do projeto, conforme se verifica nas Tabelas 1 e 11 . Da mesma maneira que aconteceu no projeto anterior, em algumas das casas, mesmo numa em que fora demolido e reconstruído o quarto de dormir, o $P$. meg:stus não foi erradicado.

TABELA I

Resultado do Levantamento com Desalojante Piriza antes a aplicaçä̊o de Malathion (janeiro de 1973)

\begin{tabular}{|c|c|c|c|c|c|c|c|c|c|c|c|}
\hline \multirow[b]{2}{*}{ Plano } & \multirow[b]{2}{*}{ Localidades } & \multicolumn{4}{|c|}{ Casas Pesquisadas } & \multicolumn{5}{|c|}{ Triatomineos } & \multirow{2}{*}{$\begin{array}{c}\text { No das Casas } \\
\text { Positivas }\end{array}$} \\
\hline & & Exist- & Pesq. & $\begin{array}{l}\text { Com } \\
\text { Triat. }\end{array}$ & $\%$ & Ad. & Ninf. & Total & $\begin{array}{l}\text { Horas } \\
\text { Gastas }\end{array}$ & $\begin{array}{l}\text { Média } \\
\text { Horá- } \\
\text { ria }\end{array}$ & \\
\hline \multirow{4}{*}{ 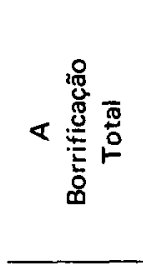 } & Graviel & 24 & 22 & 5 & 23 & .28 & 4 & 32 & 5,6 & $, 5,7$ & $20,3,2,18,1$. \\
\hline & Caco & 20 & 17 & 9 & 53 & 53 & 30 & 83 & 4,5 & 18,4 & $\begin{array}{l}18,19,17,2, \\
3,15,12,4 . \\
\end{array}$ \\
\hline & Alto & 23 & 21 & 3 & 14 & 7 & 2 & 9 & 4,6 & 1,0 & $16,17,18$ \\
\hline & Riacho Sêco & 29 & 26 & 7 & 27 . & 18 & 8 & 26 & 5,9 & 4,4 & $\begin{array}{l}15,20,19,23 \\
2,9,3 .\end{array}$ \\
\hline Sub-Total & & 96 & 86 & 24 & 27 & 106 & 44 & 150 & 20,6 & 7,2 & \\
\hline \multirow{4}{*}{ 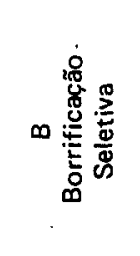 } & Cajueiro & 19 & 19 & 4 & 21 & 26 & 26 & 52 & 3,4 & 15,2 & $18,5,8,11$ \\
\hline & Coqueiro & 14 & 13 & 2 & 15 & 4 & 4 & 8 & 1.7 & 4.7 & 10,6 \\
\hline & M. Genipapo & 10 & 10 & 3 & 30 & 13 & 6 & 19 & 2,0 & 9,5 & $5,10,9$ \\
\hline & Morro & 7 & 7 & 3 & 43 & 19 & 4 & 23 & 1,5 & 15,3 & $3,1,5$ \\
\hline Sub-Total & & 50 & 49 & 12 & 24 & 62 & 40 & 102 & 7,2 & 14,1 & \\
\hline Controle & M. Afonso & 48 & 41 & 8 & 19,5 & 20 & 7 & 27 & 8,4 & 3,2 & $\begin{array}{l}13,19,23,29 \\
30,32,2,33,41 \\
\end{array}$ \\
\hline Total: & & 194 & 176 & 44 & 25 & 188 & 91 & 279 & 36,6 & 7,6 & \\
\hline
\end{tabular}


TABELA II

Resultado do Levantamento com Desalojante Piriza, seis meses após a última das 3 aplicações com intervalos semestrais, de Malathion, (março de 1975)

\begin{tabular}{|c|c|c|c|c|c|c|c|c|c|c|c|}
\hline \multirow[b]{2}{*}{ Plano } & \multirow[b]{2}{*}{ Localidade } & \multicolumn{4}{|c|}{ Casas Pesquisadas } & \multicolumn{5}{|c|}{ Triatomineos Capturados } & \multirow{2}{*}{$\begin{array}{l}\text { Número das Casas } \\
\text { Positivas }\end{array}$} \\
\hline & & Exist. & Pesq. & $\begin{array}{l}\text { Com } \\
\text { Triat. }\end{array}$ & $\%$ & Ad. & Ninf. & Total & $\begin{array}{l}\text { Horas } \\
\text { Gastas }\end{array}$ & $\begin{array}{l}\text { Média } \\
\text { Hor. }\end{array}$ & \\
\hline \multirow{4}{*}{ ৫总 } & Graviel & 24 & 22 & 3 & 14 & .4 & 0 & 4 & 5,0 & 0,8 & $2,5,18$ \\
\hline & Caco & 17 & $\begin{array}{l}17 \\
\end{array}$ & 3 & 18 & 5 & 12 & 17 & 3,0 & 5,7 & $6,17,18$ \\
\hline & Alto & 23 & 23 & 2 & 9 & 4 & 5 & 9 & 4,0 & 2,2 & 6,18 \\
\hline & Riacho Sêco & 29 & 29 & 0 & 0,0 & 0 & .0 & 0 & 6,0 & 0,0 & - \\
\hline Sub- Yotal & & 93 & 91 & 8 & 9 & 13 & 17 & 30 & 18,0 & 1,7 & \\
\hline \multirow{4}{*}{ 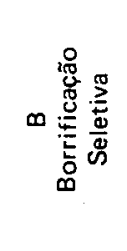 } & Cajueiro & 16 & 16 & 0 & 0,0 & 0 & 0 & 0 & 2,0 & 0,0 & - \\
\hline & Coqueiro & 12 & 11 & 0 & 0,0 & 0 & 0 & 0 & 1,5 & 0,0 & - \\
\hline & M. Genipapo & 10 & 7 & 2 & 28,5 & 2 & 3 & 5 & 1,4 & 3,5 & $5,10$. \\
\hline & Morro & 6 & 6 & 2 & 33 & 2 & 1 & 3 & 1,3 & 2,3 & 3,5 \\
\hline Sub-Total & & 44 & 40 & 4 & 10 & 4 & 4 & 8 & 6,0 & 1,3 & - \\
\hline Controle & M. Afonso & 38 & 37 & 10 & 27 & 32 & 0 & 32 & 6,0 & 5,3 & $\begin{array}{r}1,13,21,29,30 \\
32,33,37,39,40 \\
\end{array}$ \\
\hline Total: & & 175 & 168 & 22 & 13 & 49 & 21 & 70 & 30,0 & 2,3 & \\
\hline
\end{tabular}

\section{CUSTO OPERACIONAL}

Na prática, para a borrifação de $142 \mathrm{~m}^{2}$ de paredes de uma casa, gastamos cinco minutos e foram consumidos $308 \mathrm{~cm}^{3}$ de malathion.

Para a borrifação de 103 casas por dois guardas, durante três dias, foram gastos 40 litros de malathion.

Pode-se deduzir que o volume médio de inseticida gasto por casa, que tem uma área média de $150 \mathrm{~m}^{2}$, foi de $350 \mathrm{~cm}^{3}$ de malathion. Por dia, foi possivel a borrifação de 15 casas por um guarda, na área rural. Em cidades e vilas a quantidade de casas que se podem borrifar é certamente maior, devido à proximidade das mesmas.

Para determinar o preço atual de uma borrifação com malathion, podemos nos basear nos seguintes dados.

Para a borrifação de 15 casas num dia, realizamos as seguintes despesas:
- uma diária do guarda borrifador $\operatorname{Cr} \$ 42,00$

- meia diária do motorista

$\mathrm{Cr} \$ 21,00$

- uma diária do supervisor técnico $\operatorname{Cr} \$ 121,00$

- gasolina e outras despesas $\quad \operatorname{Cr} \$ 30,00$

- malathion (5,25 litros) $\quad \operatorname{Cr} \$ 184,00$

Custo para borrifar 15 casas $\quad \overline{C r} \$ 398,00$

Custo para borrifar 01 casa $\quad \mathrm{Cr} \$ 26,50$

O custo de vinte e sete cruzeiros para a borrifação de uma casa está elevado. Devemos, porém, levar em conta que os cálculos foram feitos com a inclusão das despesas de um supervisor técnico, o qual normalmente não é necessário nos trabalhos de rotina. Dessa forma, o custo operacional real para a borrifação de uma casa com malathion será aproximadamente de dezoito cruzeiros.

Embora o preço de um kilo de BHC esteja custando quase a metade do preço de um litro de malathion, o custo operacional atual, com base nos mesmos gastos gerais para a borrifação de uma casa com BHC, é de trinta e quatro cruzeiros, portanto quase o dobro do custo do malathion. 


\section{COMENTÁRIOS E CONCLUSÕES}

O malathion, pelos dados que apresentamos, mostrou potente eficácia no combate ao $P$. me gistus, principal vetor da Doença de Chagas no Estado da Bahia. Ao lado da ação letal sobre as formas ambulantes do inseto, a eficácia do inseticida para o controle do triatomíeno, foi também, sem dúvida, em grande parte, devida a sua ação ovicida.

Os nossos dados mostraram que houve uma queda drástica no índice de infestação domiciliar e na densidade domiciliar de triatomíneos, tanto na área como aplicações semestrais seletivas das casas positivas como na área de borrifação total. Deve-se ter em mente, entretanto, que a eficácia na área seletiva não é tão boa como parece, pois deve-se levar em conta que, além de ter sido a população de triatomíneos, espoliada periodicamente pelos inquéritos semestrais com piriza, também três das 12 casas dessa área, inicialmente infestadas, tiveram seus dormitórios demolidos e reconstruídos. Isto certamente mascarou o índice de infestação que se obteria somente com o emprego do malathion, tendo sido assim exagerada a eficácia do inseticida com esse método seletivo de borrifação.

Pọrtanto, o método de borrifação a ser escoIhido numa campanha de combate aos triatomíneos com malathion deverá ser o de borrifação de todas as casas, o qual, além de ter mostrado maior eficácia, irá custar menos em verba, trabalho e tempo do que uma campanha feita com o método de aplicação seletiva do inseticida, isto é, só nas casas periodicamente demonstradas positivas pela piriza, que é um produto caro. Além do mais, como sabemos ${ }^{6}$, a negatividade de uma casa inspecionada com piriza não significa que essa casa, obrigatoriamente, não esteja infestada por triatomíenos. Aliás, é nossa opinião, que o método de borrifação de todas as casas, pelo menos durante os dois primeiros anos, deva ser o método de escolha para as campanhas com qualquer tipo de inseticida $e$ não só com o malathion ${ }^{8}$.

Entretanto, como o malathion não desodorizado, após alguns dias de aplicação, deixa um desagradável odor de matéria orgânica em decomposição, e esse odor desagradável perdura por algum tempo, talvez seja interessante que, controlado o triatomíneo a um nivel insignificante de densidade, as aplicações de manutenção desse inseticida possam ser feitas apenas nas casas que continuassem positivas nos reco- nhecimentos posteriores com piriza, na fase de vigilância. Aliás, para sanar esse inconveniente. é possivel ainda empregar-se o malathion desodorizado, ou seja o Cityon, bem mais caro, no entanto, que o malathion simples.

Quanto ao custo operacional do malathion vịmos que não é tão elevado e Martinez e cots. ${ }^{4}$ o calcularam cerca do $1 / 4$ do custo do BHC Atualmente, na Bahia, o custo operacional para a borrifação de uma casa com $\mathrm{BHC}$ é de trinta e quatro cruzeiros, enquanto que, com o malathion, calculamos aproximadamente dezoito cruzeiros. O custo operacional é muito mais baixo, por causa do método de aplicação, pois o tempo gasto com o malathion é cerca de $50 \%$ menor do que o.tempo exigido pelo $\mathrm{BHC}$ para a borrifação do mesmo número de casas, ou seja, a borrifação por homem dia é de 15 casas com o malathion e 6 casas com o BHC.

Infelizmente, apesar da eficácia do malathion através de sua ação letal sobre formas ambulantes e ovos, o $P$. megistus resistiu a ser erradicado do domicílio humano, o que também verificamos com outros inseticidas ${ }^{7}$. Talvez seja esta a explicação para um fato que é atualmente bastante comentado no Sul do Brasil, ou seja, o da "substituição especifica" de $T$. infestans pelo $P$. megistus ou outras espécies de triatomíneos, após as medidas profiláticas com BHC. $\dot{E}$ provável que esteja havendo uma interpretação errônea para esse fato, o qual na realidade representa apenas a maior resistência que o P. megistus tem demonstrado aos inseticidas para ser erradicado dos domicílios, em comparação com $T$. infestans e outros. Dessa forma, os remanescentes do $P$. megistus que ficaram escondidos nas frestas das paredes e resistem alí a prolongado período de jejum, seriam os repovoadores responsáveis pela reinfestação das casas tratadas, embora ao lado deles possa ocorrer, também, o fato de que exemplares vindos do exterior também contribuam para o repovoamento e colonização do domicílio humano.

Finalizando, concluimos que o malathion deve estar na primeira linha de escolha de um inseticida para ser usado em amplas campanhas de combate aos vetores de doença de Chagas, principalmente nas áreas em que esses vetores sejam $P$. megistus ou $T$. infestans. Para esta última espécie, os resultados obtidos por Martinez e cols. ${ }^{4}$, em campanhas experimentais feitas na Argentina, foram excelentes. Infelizmente não existem ainda dados referentes à eficácia do malathion no controle do $R$. prolixus. 


\section{AGRADECIMENTOS}

Não podemos deixar de registrar os nossos agradecimentos aos dirigentes da "BLEMCO" entre os quais o Dr. Milton Marchesi, por nos terem fornecido o inseticida e colaborado com parcela financeira para a realização das observações de campo. Os agradecimentos são especiais ao engenheiro agrônomo dessa Companhia, Dr. Marcelo Dowsley, que muito nos ajudou nos trabalhos de campo.

\section{SUMMARY}

Concentrated Malathion was used against Panstrongylus megistus, the principal local vector of Chagas' Disease, in an endemic area in the State of Bahia, Brasil.

The efficacy of malathion in the controle of this triatominae was demonstrated after three applications six months apart. The insecticide is lethal to all stages of vector including the eggs.

In view of its effectiveness in the control of the triatomine, the absence of any noticeable signs of intoxication in the personnel applying the insecticide and in residents of the treated houses or domestic animals, and the relatively low operational cost, the Authors conclude that malathion is a valuable weapon in campaigns to control the vectors of Chagas Disease.

\section{REFERÊNCIAS BIBLIOGRÁFICAS}

1. ALANIA, R.I. \& GONZALES, F.F. Adaptacion de la maquina pulverizadora a mochila motor "Capri" para la aplicacion de malathion a ultra bajo volumen. Apresentado nas "Jornadas fito-sanitárias da Faculdade de Agronomia da Universidade de Buenos Aires. Mimiografado, 1971.

2. CULVER, D., CAPLAN, P. \& BATCHELOR, G.S. - Studies of Human Exposure During Aerosol Application of malathion and Chlorthion. A.M.A. Archives of Industrial Health 13:37-50, 1956.

3. LEAL, J.M., SHERLOCK, I.A. \& SERAFIM, E.M. - Observações sobre o combate aos triatomineos domiciliares com BHC em Salvador, Bahia. Rev. Brasil. Malar. D. Trop. 17:65-73, 1965.

4. MARTINEZ, A., CHICHERO, J.A., ALA. NIA, I.R. \& GONZALES, F.F. - Control of Triatoma infestans with malathion concentrated. J. Med. Ent. 11.653-657, 1975. $11: 653-657,1975$.

5. Public Health Pesticides - Reprinted fron Pest Control - the Harvest Publishing Company. 21 pp. U.S.A., 1973.
6. SHERLOCK, I.A. - Field evaluation of inseticides. International Symposym on new approaches in American Trypanosomiásis research. P.A.H.O. - B. Horizonte, Brazil 18-21 March, 1975.

7. SHERLOCK, I.A. \& MUNIZ, R.M. Observações sobre o combate ao $P$. megistus com BHC em área infestada do Estado da Bahia, Brasil. Rev. Brasil. Malar. D. Trop. vol. 26 (em publicação).

8. SHERLOCK, I.A., MUNIZ, T.M. \& GUITTON, N. - A ação do malathion sobre os ovos de triatomíneos vetores de doença de Chagas. Rev. Soc. Brasil. Med. Trop. (em publicação).

9. SHERLOCK, I.A. \& SERAFIM, E.M. Fauna Triatominae do Estado da Bahia, Brasil. 1. - As espécies e distribuição geografica. Rev. Soc. Brasil. Med. Trop. $6: 263-289,1972$.

10. SHERLOCK, I.A. \& SERAFIM, E.M. Fauna Triatominae do Estado da Bahia, Brasil. VI - Prevalência geografica da infeccão dos triatomíneos por $T$. cruzi. Rev. Soc. Brasil. Med. Trop. 8:129-140, 1974. 